\title{
Quality of Informing: Bias and Disinformation Philosophical Background and Roots
}

(Research in Progress)

\author{
Zbigniew J. Gackowski \\ California State University, Stanislaus, CA, USA
}

\section{ZGackowki@.csustan.edu}

\begin{abstract}
This is an inquiry into the background and the origins of bias and disinformation as viewed from the philosophical perspective. This paper demonstrates the undeniable analogy between the philosophical framework defined by Schopenhauer and the informational model of decision situations as viewed today in operations research, management sciences, and decision sciences. Bias, and disinformation - the main concerns of informing science are not aberrations or deviationsare the very nature of all communications among living entities. Within the realm of informing science, research that ignores this fact may produce unreliable results. One must face this reality head on. The inquiry contributes to the theoretical foundations of informing science. The results are presented for challenge, critique, and discussion.
\end{abstract}

Keywords: Informing, bias, misinformation, disinformation, theoretical foundations, entity informed

\section{Introduction}

Eli Cohen (1999) defines informing sciences as "the field of inquiry that attempts to provide a client with information in a form, format, and schedule that maximizes its effectiveness" (p.5). This paper examines the dynamic process of informing with respect to the credibility of its content (information value) in addition to the form and format that play an indirect role in determining its quality. In contrast to a different paper, "Quality of informing: Credibility-a provisional model of functional dependencies," this one focuses on the philosophical background and the inherent roots of bias and disinformation. They are the greatest risks associated with informing. Thoughts about mitigation strategies are discussed. According to Eli Cohen, bias is a failure to fully inform, and disinforming is reporting untrue information as true, with knowledge that it is not true. Its purpose is to deceive.

This inquiry attempts to identify the underlying cause(s) of bias and disinformation and to demonstrate that bias is more than "failure to fully inform." The latter is the least harmful kind of

Material published as part of this publication, either on-line or in print, is copyrighted by the Informing Science Institute. Permission to make digital or paper copy of part or all of these works for personal or classroom use is granted without fee provided that the copies are not made or distributed for profit or commercial advantage AND that copies 1) bear this notice in full and 2) give the full citation on the first page. It is permissible to abstract these works so long as credit is given. To copy in all other cases or to republish or to post on a server or to redistribute to lists requires specific permission and payment of a fee. Contact Publisher@InformingScience.org to request redistribution permission. bias, which is caused by ignorance, and belongs to misinforming, which is not a subject of this paper. This inquiry deals with the bias rooted in human nature, in its subconscious and intentions, which make it part of disinforming.

This paper refers to the theoretical operations research-based approach to informing and to operations quality of data and information values as proposed 
by Gackowski (2004; 2005a; 2005b). The philosophical background and roots of bias and disinformation are based on Schopenhauer's opus vitae, "The world as will and representation," which was critically presented to English readers by Hamlyn (1980).

The main contributions of this paper are

- the modified concepts of informing

- the role of credibility in passive informing

- the role of credibility in active informing where bias and disinformation reign

- $\quad$ some thoughts about mitigating disinformation and intentional bias

For focused reading, key terms in paragraphs are in bold font, emphasis in italics, highest emphasis underlined, and terms followed by a definition in bold italics.

\section{Informing Systems as We Know}

\section{Concepts of Informing}

In Nadler's (1970) terminology on work systems, "informing systems are a class of work systems whose basic output is information that affects recipients' actions" as defined by Gackowski (1982, p. 108). Since that time, a separate discipline of informing science emerged that was fostered by the incessant efforts of the Informing Science Institute, led by Eli Cohen, with an established tradition of annual international conferences, journals, and other forms of publication not horded by always shared on the Web.

Informing models comprise basic components: information source(s), communication channel(s), and informed entities. In informing science, the latter are referred to as clients. In the conventional meaning of the term in commerce, networked computers, or program objects, however, they may not always be clients. The term "entities informed" renders better their role and position in informing.

Information sources may be active or passive.

- Active information sources - informing entities by their nature or design transmit, disseminate, or broadcast signals conveying information. When by design, sources are active agents - senders or disseminators of information, such as advertisers, professional information providers, politicians, preachers, etc.--the entities inform or try to affect them in a desired manner.

- Passive information sources yield information when observed, examined, and/or measured.

Communications channels link information sources and entities informed. The sets and sequences of signal transformations constitute the informing processes. They may be performed by any component of the informing model: informing entities, and/or communication channels, and/or entities informed. Usually they are functions of information delivery and distribution systems that constitute one of the three major components of the informing science framework as defined by Cohen (1999).

Clients or entities informed (marketing prospects, competitors, adversaries, students, voters, public, robotic devices, etc.) must be capable of acting autonomously so that the incoming information may make them behave differently than otherwise. Entities informed may be simple or composite entities, individuals or organizations, even robotic devices that are controlled numerically or by artificial intelligence. Within entities informed, division of labor may result in specialized 
sub-entities that deal with information acquisition and its presentation, decision-making and implementation, and the acting agents. Entities informed may be targeted intentionally by disseminators of information, or they may actively gather information from sources. Hence, they may be interested in being provided with some information products or services. They may pay for being informed or seek only information offered seemingly free. They may also be inclined to enter into a dialog to refine the informing process or refuse to participate in it.

There are several universal conditions for successful informing. For informing to take place, there must be a difference in states of the information source and the entity informed with regard to the transmitted signals. In communications theory, the difference is measured by entropy ${ }^{1}$. With no difference in the states of sources and the entities informed (they know the same), their respective levels of entropy are the same. After informing has occurred, the respective states of the source and the entity informed are equal, hence, the received information values ${ }^{2}$ - their content was not known to them. The information values must meet several quality requirements to become first operationally usable $^{3}$ and, next, useful $^{4}$ by becoming effectively operationally complete to a degree that triggers a transition of the operations state (to act or not) (Gackowski, 2005b).

There is always a defined or at least implied purpose of informing viewed from the perspective of the informing entities and/or the entities informed. The purpose may constitute any utility value of commercial, administrative, military, and educational, entertainment, social, or even only personal nature. Whatever the purpose, one is interested in high-fidelity transmission of signals, which is a technical problem. With the exception of entertainment, all informing is of problematic credibility. Even entertainment fostering, conveying (directly or indirectly) life styles, attitudes, and behaviors of the entertaining entity is not without bias.

Problems with credibility of data or information values are mostly non-technical. They are inherent to all communication among living entities, including humans-usually deceptive but always biased for their purposes. Some bias may be attributed to ignorance; however, most of the bias or lack of objectivity is deeply rooted in all living nature. It is a conscious or subconscious deviation from the truth-only truth and the entire truth. Bias, except the unintended, should not be described as "failure to fully inform." The term "failure" implies that one intended to be objective and truthful but somehow failed in this respect. Even most of the unintended misinformation comes from various human imperfections and fallibility, much less from technical problems. Simply the purpose of communications taints them with bias and tempts to disinform.

Informing may be direct or indirect, solicited or unsolicited, by entities informed.

- In direct informing, information flows directly between information sources and entities informed.

- In indirect informing, intermediary acquisition, processing, retrieval, delivery, and presentation of information takes place between information sources and entities informed. In

\footnotetext{
${ }^{1}$ A measure of the disorder or randomness in a closed system that consists of the source and the clientnumber of bits necessary to transmit a message as a function of the probability that the message will consist of a specific set of symbols.

${ }^{2}$ Represent things, events, and unknown states that are yet to be acquired, which change the decision situations per se, and/or the actions that implement the decisions, and/or the results of operations.

${ }^{3}$ A data or information value becomes operationally usable when it jointly meets all of its universal (acquisition interpretable, of significant impact, operationally timely available, actionably credible), and situationspecific (for instance, exclusively available) mandatory quality requirements. Usability does not imply effectively usable.

${ }^{4}$ A usable data or information value can become operationally useful only as a member of an operationally effectively complete activity-specific cluster of required operationally usable data or information values.
} 
an advanced environment, data are organized in databases or data warehouses. These may be run by informing entities or by entities informed for them.

The design and examination of informing systems differs considerably for active and passive informing. In case of active informing, informing entities try to provide gainfully some information service and/or influence the behavior of the targeted entity informed. Usually, their perspective carries more weight than the perspective of entities informed, because the former affect the behavior of many entities informed. In passive informing, the entity informed may purposefully try to gather intelligence about the environment or obtain some feedback about the state of the situation under consideration if the results differ or may differ significantly when acting without the obtained information. In either situation, informing entities and entities informed aim at measurable or at least perceivable results of some utility value or payoff. Hence, in cost-aware business environments, when one aims at achieving the best results, one should carefully examine the expected cost effectiveness of the respective informing systems. A graphical schema of informing is in Gackowski (2005a).

Up to this point, the basics of informing are rather clear and not controversial; however, once one touches the purpose of informing, the issue becomes murky. The entire problem can be divided into the purpose of passive and the purpose of active informing. In both cases, credibility remains the main issue. For most cases of passive informing, credibility may be examined in a relatively objective manner. In active informing, a new source of problems emerges-intentionality. The latter requires different methods of examination, which belong to higher planes of a philosophical inquiry.

\section{Credibility in Passive Informing-Overview}

A provisional model of credibility exists that is based on and derived from the model of operations quality of data and information values. It was presented at the $10^{\text {th }}$ Anniversary ICIQ-2005 Conference at MIT by Gackowski (2005b, 2006a). It identified the universal quality requirements and the universal principles governing operations quality. The latter publication presents a credibility model that attempts to identify all functional dependencies of the direct quality requirement of actionable credibility on the indirect operations quality attributes with the corresponding entity-relationship diagrams.

Credibility of a data/information value means whether it is true-whether one may rely on the value. The adjective true means consistent with reality. Complete credibility is hence rarely to never attainable. If it is Boolean (true, false), its degree is measured by the probability of its veracity $(0-1)$. While probing for veracity of data or information values, users/entities informed face dramatic options, less with data of well-established roles and more with unknown recently acquired information values. The question is whether they received disinformation, misinformation, or valid information. To this end, outright disinformation must be excluded first, and the degree of misinformation assessed next. Only then must the concerned value be tested for validity.

Disinformation intentionally misinforms. On the one hand, it may not be clear who the originator is due to omission of contact addresses, when it was originated or updated, what methods of collection or acquisition were used, etc. On the other hand, all the above may be available. Now, however, the entity informed faces two extremes of deception with many possibilities in between. All indicators of validity are given to legitimize the value, but one or more of them are false, or they all are true to convince and trap the gullible in a desired manner.

Misinformation unintentionally misrepresents reality. It may be distorted at its acquisition, communication, storing, processing, presentation, and its interpretation. It may be of lesser or higher 
materiality, as required and defined by FASB (1983). In operations, it is determined by the impact a value exerts on them.

Valid information faithfully represents reality. To this end, it should be well defined, of known variability, objective (unbiased), accurate (error free), precise, and current (up to date). Usually, the above is attributed to the reputation of the source; can be traced back to the responsible originator, where the level of responsibility is adequate to the potential consequences (in operations) of the expected errors; and when information is of proven authorship, can be replicated, or can be confirmed otherwise.

Affecting factors may be classed into positive and negative ones. It seems that only the variety or the number of independent sources increases credibility of data/information values. Sources of data or information values may be observers, sensors, processes, tests, etc. Any data/information value acquired from a specific source inherits credibility from the reputation of its source labeled source-specific credibility. Joint credibility may be impaired by imperfections in mapping quality of values, as defined by Wand and Wang (1996), within the data and information delivery system and its presentation credibility to entities informed.

Actionable credibility of data or information values is attained when joint credibility equals or exceeds the threshold for a state transition of operations (to act or not) as defined by the policy in effect. Economical actionable credibility imposes additional economical requirements (Gackowski, 2005b); for instance, the cost of attaining it should not exceed the benefit the value adds to operations.

This overview covers only the direct functional dependencies of the joint credibility. Most of the direct factors depend again on indirect quality attributes of the first order. Many of the latter may again functionally depend on other indirect attributes of the second and subsequent orders (Gackowski, 2006).

\section{Credibility in Active Informing- Roots of Bias and Disinformation}

All the aspects of credibility of data/information values discussed in passive informing should also be taken into account in active informing. However, two major differences pertain to disinformation and bias as defined before. Bias may occur in all types of informing, although in passive informing its source is ignorance; hence, it is classed as an aspect of misinformation. It is unthinkable that individuals and organizations seeking out information values would on purpose introduce bias for themselves, although subconsciously, they may do it. Being delusional, they may seek or accept only information that is music to their ears. This aspect is not a subject of this paper.

The main subject of this section is the natural tendency of anything living toward bias and outright disinformation. In active informing, bias and disinformation reign. They are the natural allpervasive features of active informing. Once one enters the realm of intentions, one literally descends into murky, foggy realms of human spirit, aspirations, and drives that are difficult to fathom. Informing science is fortunate that these most difficult problems seem to be satisfactorily elucidated within the philosophical framework developed by Arthur Schopenhauer. The edifice of Schopenhauer's philosophical thought seems to be adequate to this human non-technological realm of informing science. From the decision-science and informing-science perspective, there is a striking analogy between the contemporary model of decision situations and Schopenhauer's "The World as Will and Representation"-between the world of data and information values that represent the reality and the will of decision makers or decision-making bodies. It pertains to all kinds of informing, active informing in particular. 


\section{The world as will and representation}

This is the title of Schopenhauer's opus vitae, which is critically presented by Hamlyn (1980). It contains the essence of his views of how the world functions. The model consists of will and representation. All processes are interplays between them. The model applies to all subjects. It is a logical equivalent to a contemporary information model of decision situations in which one takes inventory of what is already known by the decision maker (data), what is not yet known and must be acquired (information), and the applicable rules of reasoning (knowledge). These are the equivalents of Schopenhauer's representations. Subjects, here decision-makers, never act on the basis of the actual reality, for it is never fully known. They act based on the available purported representations of that reality. Schopenhauer's model is clearly bipolar and very incisive with regard to bias and disinformation, which are subjects of this paper. All representations are conditioned by other representations. There exists, however, an unconditioned awareness of willing. We can learn a lesson from Schopenhauer concerning the nature of action and the will and thereby concerning the place of human beings in the scheme of things. The governing principle of human existence is the will to live; i.e., egoism. The all-dominant force of the will looms large in his model, where only intellect plays the role of quieter of the will (Hamlyn, 1980).

Representation - In operations, decision-makers and/or acting agents become aware of the situation they are in by using direct and indirect sources. The direct sources comprise everything that is perceived by their senses or sensors. The indirect sources comprise values (the content) of symbolic representations (data values, information values, and knowledge meant as rules of reasoning) available to them. Decision-makers consider them in the situation they are in and the challenges they face and must deal with.

According to Schopenhauer, however, for the subjects (decision-makers in operations), representations are the only objects, the only empirical reality to them (Hamlyn, 1980, p. 65). They are in no casual relationship with the subject. Causality applies only to and within representations. All representations are subject to conditions, which constitute one of the four forms of the principle of sufficient reason, as defined by Schopenhauer in his doctoral dissertation (Hamlyn, 1980, p. 7). Every representation is relative to another representation that is its condition, ground, or reason. At the same time, Schopenhauer stands on the ground of "realistic dogmatism" (there really is an object separate from the subject and the representation that exists for it) and skepticism (we can never know of any real thing that lies behind representations). Nevertheless, the conditioned nature of all representation is an a priori truth in general and in detail.

We know, however, that at the lowest level of the operations hierarchy, actors or acting agents are in direct contact with tangible elements of reality - the means and objects of their actions. The higher the level of management or command (supervisory, tactical, strategic), the lesser the direct contact with reality and the higher the dependency on their substitutes-representations. At the highest level of operations, subjects act indeed only within a virtual reality of the representations available to them and their will. Schopenhauer claims that even the direct sensations, in the process of their understanding, are converted into perceptions that, in turn, provide subjects with the corresponding representations. Even when one does not accept Schopenhauer's argument that all sensations appear to the human mind as representations, it still holds true for the higher levels of decision-making in particular, where subjects live in the virtual world of representations and the will of their chief executive officer or commander-in-chief.

When one excludes incidents when decision-makers directly witness events or directly act to implement their decisions, there is nothing more left than the representations in the form of available data values, obtained information values, and known rules of reasoning. When one also considers the phenomenological aspects of reality, even intuition can be added. This, however, brings us beyond the purely rational decision-making. Thus, within the realm of operations, one cannot 
deny the strong analogy of Schopenhauer's world of representations and the contemporary reality in which decision-making takes place. The same holds true in one or other form to all devices controlled numerically or by artificial intelligence.

Will-Schopenhauer views and defines will in a much broader manner than usual. He identifies all force with will, whether gravity or the will to live. It is the governing principle of the universe and the human existence. It leads to egoism. Will-the all-dominant force comprises all the forces of life, urges, drives, desires, ambitions, etc. (with the exclusion of reason or intellect) permeates all nature and governs all phenomena (Hamlyn, 1980, p. 95). It is the driving force of all nature, most vividly observed in all living entities, the life force that drives all their behavior, including their autonomously functioning systems that sustain their basic physiological functions. Schopenhauer goes even further and claims that an insight into our nature is an insight into the nature of reality in general.

According to Schopenhauer, will, as thing in itself, cannot be subject to space and time and the principle of sufficient reason. Will is only one; it lies outside the possibility of plurality. However, it objectifies itself in human beings, animals, and organic life, and even in inorganic matter. This part again lies beyond the boundaries of informing science and operations.

Will is a sufficient reason to act, but it also is subject to causality, called motivation. It implies that a force is not a cause; it is what gives cause a possibility of acting (Hamlyn, 1980, p. 77). Will has no end or purpose; the latter are products of the intellect. Motives are causes seen from within. A chain of representations experienced by a decision-maker may lead to the ultimate motive of the decision to trigger a system of operations aimed at attaining a defined purpose. This represents causality viewed from the inside. The ultimate motif is another form of sufficient reason of human actions called the principle of motivation. It is the major guide in history, politics, pragmatic psychology, etc. in human endeavors and operations. Motive, if studied from the viewpoint of its value and sources, is a guide in ethics. Due to the fact that human beings have a direct and unconditional awareness of the will, they act in a true sense; animals and controlled devices only react to stimuli. The will of acting subjects has many degrees, beginning with the most silent wishes up to unchecked passions; not only the subjects' feelings but also the slightest movements of their mood are states of will.

The will is absolutely egoistic and directly opposed to morality. It is untiring and incessant. Its only objective or end is its continuity; thus, it promotes self-deception and deception of others (ibid., pp. 98-100). It manifests itself in growth, expansion, and preservation of individuals and species in fierce competition for resources (territory, water, food, etc.). It leads to eternal universal clash of divergent interests. There also is no absolute necessity, only necessity relative to something else. The principle of sufficient reason is the sole support of all necessity. This is Schopenhauer's rationalism. Thus, the will (as defined before) is also the source of inevitability of bias and disinformation, as we know. They are not exceptions; they are the actual reality that must be expected and faced head on. When will is a sufficient reason to act, then by the same token, the same will that blindly tries to impose itself on other subjects is a sufficient reason for all intentional (the conscious and subconscious) bias and disinformation. There also exists, however, biases due to ignorance-not a subject of this paper.

Such a consistent model based on incisive observations of reality of the human conditions and behavior possesses some explanatory and predictive features. On the one hand, Schopenhauer repudiates Kant's practical reason because of its connection to morality. He leaves room for practical reason whenever one acts from abstract principles, goals, or ends abstractly conceived, which fully applies to purposive operations. On the other hand, Schopenhauer's philosophy is very ethical and moral, but it is based on the principle of checks and balances that the human intellect may exert upon the blind drives of the will. The concept is similar to blind economic forces 
of free markets channeled by the framework of a proper legal system and the checks and balances, as in the American constitutional order that launched one of the most productive societies. Both were developed based on the pessimistic assumption of the egoistic nature of humans and succeeded better than other societies that proclaimed idealistic goals and natural goodness of humans. Schopenhauer considers even optimism as an immoral way of thinking.

Due to the incisiveness, adequacy, rigor, and consistency of his framework, most of Schopenhauer's contemporaries preferred to remain silent. Some recognition was given to him only at the end of his life. He was held in the highest esteem by Nietzsche, but in the next century, his works became necessary reading for everyone who was interested in the humanities. Of course, today's critiques of philosophical arguments raise many objections to his worldview. One of the objections is that Schopenhauer claims that the will (as defined by him) pertains to all objects of the universe, which is beyond the realm of informing science. Certainly, his view pertains to the entire animal world. Schopenhauer claims that any attempt to portray any object (representation) that did not conform to the principle of sufficient reason in one of its four forms, as defined by him, would be unintelligible. He freely admitted the impossibility of proof of it. The argument is dialectical only. But from the more limited perspective of operations, as long no one can find any example to the contrary, it is a sufficient proof. As long as it holds true, any labeling of his model as indicative of rationalism or idealism is irrelevant in operations. Hamlyn (1980, p. 163) concludes that none of the philosophical objections means that we have no reason to listen to what he has to say about human beings, although they are pessimistic. Philosophy is not merely an academic discipline that only extends our understanding of things. It can bring with it a form of resolution of the inevitable conflicts; Schopenhauer even claims the possibility of salvation from the will. Hamlyn (1980) concedes that "Schopenhauer's philosophy remains a magnificent intellectual construction, from which there is still much to learn" (p. 170).

\section{Freedom of the will}

In 1839, the Norwegian Scientific Society organized a competition. The question set was whether it is possible to prove the freedom of the human will from its own consciousness. Schopenhauer gave a resounding "No." He won the competition. There is no such thing as an absolute free will. He sets against it his own view of necessity as expounded in his doctoral dissertation in the "Fourfold root of sufficient reason" (Schopenhauer, 1974). All phenomena are subject to the principle of sufficient reason - causality. Similarly, our actions are determined by motives. Will alone, as defined by Schopenhauer, is not. It "knows no necessity" and "is not determined as consequent through a reason” (Hamlyn, 1980, p. 132).

There is, however, a relative freedom that we humans find in our consciousness. By deliberations, our intellect enables us to reflect on our motives and put off immediate actions. Thoughts that deliberations produce still function as motives. A mere image created by thoughts can act as a motive. There is no final freedom from the causal necessity that motives provide even here. At least in part, people confuse this relative freedom with real absolute freedom. What we do is subject to motives, but which motives we follow or respond to is a reflection of our individual character. According to Schopenhauer, the freedom of the will does not warrant attribution of responsibility to our deeds, but because they are a reflection of our individual character. At all times a man does what he wills, but he does it necessarily (Hamlyn, 1980, p. 127). In the realm of action, causality is all-pervasive and all-operative. We do not always act on the immediate motive but on the strongest motive, even when it requires thought for it. What a man is will determine how he acts. Cannot people change? According to Schopenhauer, people can change only with respect to knowledge, not of will (Hamlyn, 1980, p. 128). And here lies the key to some constructive solutions. 
According to Schopenhauer, only contemplation of art and knowledge acts as quieter of the will as defined by him. The will cannot be abolished by anything else except knowledge (Hamlyn, 1980, p. 150). By deliberation, knowledge enables men to shift their focus from the immediate to the less immediate but frequently stronger motives, from their individual egoism to an enlarged form of egoism (Hamlyn, 1980, p. 145). In his ethics (knowledge of morals) (Hamlyn, 1980, p. 136), wrong is a matter of an individual will being overridden by another, while the doctrine of right is simply one concerned with the limits that should be put on that, given that there is, in the end and in reality, no difference between wills in society (Hamlyn, 1980, p. 138). Thus, Schopenhauer leaves room for knowledge in her role as quieter of the will, with some hope of channeling its energy from the destructive toward the constructive end of its spectrum; this leaves room for political philosophy, social sciences, public administration, and politics.

\section{Thoughts about Politics and Informing}

"The central problem of political philosophy is how to deploy or limit public power so as to maintain the survival and enhance the quality of human life. ... Political philosophy is more theoretical and normative than descriptive..... It is concerned with what ought, on various assumptions to be. It is one of the most intellectual disciplines, for it sets standards of judgment and defines the constructive purposes for the use of public power. This aspect is more urgent today than it has been in earlier periods, because mankind has at its disposal the power either to create a world civilization, where technology can benefit the human race, or destroy itself in pursuit of political myths” (Encyclopedia Britannica, Political philosophy, 2006, p. 1).

Before Schopenhauer, Hobbes stated that, without public power due to the "competitive nature of men that once more than subsistence has been achieved ... there is a war of all against all." After Schopenhauer, in the "Ruling Class," Mosca (2006) reasserted that, "in various forms there will always be a struggle for predominance" (p. 40); hence, "public laws are necessary to regulate it. Only within a framework of tolerably well-organized constitutionalism that is gradually extended to relations between states can the swiftly mounting opportunities provided by applied science be taken so that the human specie, instead of being thwarted and deformed by its institutions, can realize its full potentialities” (Encyclopedia Britannica, Political philosophy, 2006, p. 47).

When the analogy is close to perfect, one may expect that many of Schopenhauer's conclusions, once sounding as abstract as Einstein's conclusions about the physical universe, can now be empirically explored and either validated or rejected. It may represent interesting opportunities for more research.

Individual actions and massive operations, including all communications of living entities, reflect always their particular self-interest, hence intentional bias and disinformation. They are the rule, not the exception. Therefore, one must finally expect them and face them head on. One cannot eliminate but only mitigate them - channel them into a productive rather than a destructive force as one deals with economic forces and other forms of energy. Let's see what Schopenhauer, the great pessimist, says in this respect.

First, he stands firm on the position that all phenomena are subjects to the principle of sufficient reason, but will (as defined by him) alone is not. Life force and will, like any flow of any kind of energy, must be harnessed and channeled to utilize their constructive aspects while limiting their destructive aspects. The energy of the will objectified in humans is above any other known form of energy in the universe, for it is the source of all creativity, development, and progress.

To face reality means to study how, under controlled conditions, a relative equilibrium of interests of the objectified will in subjects can be maintained to mitigate the negative consequences of their conflicts. The end is to avoid unnecessary waste of resources and to encourage productiveness leading to security and a better life for all. This is the stated goal of the positivist philosophy. 
Such equilibrium is very fragile but must be attempted to maximize the productive aspects and minimizing the negative of aspects of conflicts of interest. Some imagined that it can be attained by outright equality, but this leads to death of incentives and stagnation similar to the thermal death of any closed system with all levels of energy equalized. Physicists know that any equalization means cessation of all processes and activities, including communication, hence informing.

At the highest levels of decision-making, the virtual reality (the decision-makers are in) consists of self-interested individuals (courtiers, lobbyists, accountants, lawyers, consultants, etc.) who are flexible and smart enough to bend and skew the representations at hand to their liking and interests. Thus, all interactions and communications are subject to bias at least or deadly disinformation at most. With offices and agencies staffed with well-positioned agents of adversarial interests, the situation is always open to outright disinformation. This is the real world of the FBI, CIA, M-6, ENRON, WORLDCOM, Arthur Anderson, etc.

Informing should be viewed from the perspective of informing entities and/or the entities informed. The utility value of any data or information value should be considered from either side of the supply chain. For lasting business relations, the benefits of each side are equally important. One should not overlook, however, that in active informing, the informing entities are always in a stronger position than the targeted entities informed. The latter are in an extremely vulnerable situation. They may be simply distracted, controlled, taken advantage of, damaged, hurt, and even destroyed. Their perspective is not necessarily more important, but certainly they deserve all the protection a society can afford. On the other hand, the informing entities deserve a different type of protection from piracy and other forms of theft. An excellent example in this respect is the emergence of ESBN.ORG, which provides for authors, publishers, and distributors of electronic content and media a unique Electronic Standard Book Number (ESBN). It is recognized worldwide by electronic publishing companies and electronic content providers (ESBN, 2006) and can be used to track searches, visits, downloads, transfers, copies, etc.

When looking back at the many functional dependencies of credibility that are identified in the provisional model (Gackowski, 2006, Figure 2a and 2b) what practical measures can be taken to improve the situation with regard to bias and disinformation in human communications? The provisional model identified factors that directly affect the joint credibility of D/I values: variety of sources, source-specific credibility, mapping quality, and presentation credibility. The latter two play a significant role only in indirect informing, which presently is the prevalent mode of operations.

Variety of sources turns out to be the only direct factor (but an indirect quality dimension in operations quality) that is capable of increasing credibility. It implies that, whether within society or any private domain, main efforts should be focused on creating and maintaining a viable variety of competitive sources of information. The uncertainty related to source-specific credibility or lack thereof is its complement to one ( 1 - SSC). With additional sources, the uncertainty about a data/information value declines fast (Gackowski, 2006a). One should always search for alternative or competitive data/information sources to increase the variety of independent sources and subsequently increase not one but even two direct primary mandatory quality requirements of any data/information value: operational timely availability and its joint credibility. A variety of independent sources that yield the same or similar value for the same aspect of reality reduces one's uncertainty regarding its credibility. Even when all sources are inaccurate, there is a research in progress on a theory of complementarity of extracting accurate data from inaccurate sources through integration (Gelman, 2005). Lack of access to alternative sources of D/I values and corresponding channels of communication makes anyone and any organization extremely vulnerable to bias, disinformation, and disruption of any communication. Because credibility is rarely to never fully attainable, one should try not to rely on a single source. The variety of the 
potential sources of data or information values must be examined with regard to their external and intrinsic reputation.

The external reputation of individual sources encompasses traceability of individual data/information values to their respective sources, the availability of reliable communication channels-communicable sources, the alignment of attitudes, and the alignment of interests between active informing sources and the entities informed.

Specific data/information sources must be identified first. In many cases, they may remain unknown or questionable. In non-routine operations, one may be compelled to act even without knowledge of the source(s). Otherwise, traceability of data/information values to specific sources is a mandatory prerequisite for examining their reputation, which is particularly important for repetitive operations. Traceability of data/information values means they can be unambiguously attributed to specific sources. The more important, valuable, dangerous, litigation-prone, subject of personal accountability and responsibility, and/or vulnerable to criminal activities a value is, responsible managers or commanders preserve its traceability and transparently document its handling (audit trails). "Information systems are designed so that every financial transaction can be traced. In other words, an audit trail must exist that can establish where each transaction originated and how it was processed. Aside from financial audits, operational audits are used to evaluate the effectiveness and efficiency of information systems operations" (Encyclopedia Britannica, Information systems, 2005).

Similarly, availability and reliability of communication channels between the communicable source and the entity informed is a mandatory prerequisite for further examination of their reputation. Regardless of whether informing is passive or active, there may be no viable communication channels available, or they may be vulnerable to disruption or interference. This may render some of the potential sources unsuitable or unreliable due to intermediary circumstances, which precludes their further consideration. Here, the main defense against possible interference relies on maintaining alternative channels of communication and encryption of messages. Once, the main domains of disinformation and bias were personal relationships, fraudulent activities, propaganda, and high-flying intelligence operations. With the proliferation of the Internet, networked computers, use of e-mail, and websites, entities informed are vulnerable not only to bias but also to all kinds of disinformation and destructive invasions of their computers. Under the protection of academic freedom and freedom of expression, everybody, including students, are exposed to all kinds of bias and outright disinformation, not only by unscrupulous politicians but also by teachers and professors with nearly complete impunity—no responsibility and accountability.

In active informing particularly, the reputation of D/I sources and the implied subsequent sourcespecific credibility of the values provided may be severely affected by a variety of factors of biological, personal psychological, sociological, economical, and political nature. All of them may become consciously and subconsciously reasons for disinformation and bias in all types of communications - called here alignment of attitudes and interests. Both may decrease or increase the reputation of any source. They are of paramount overriding importance and determine the source-entity informed specific bias and disinformation. They may even preclude some of them from becoming legitimate and admissible sources of information. It works in two ways. On the one hand, the active source may exclude certain entities from providing them with information when they have been blacklisted for good or bad reasons. On the other hand, entities informed and other entities informed may outright exclude certain sources as not reputable, too questionable, or suspect.

Alignment of attitudes frequently plays such a strong role that it overrides even obvious conflicts of interest. Their intensity may vary from an irreconcilable armed death-and-life conflict 
through neutrality to a love-to-death affair. It may play a role in personal, family, tribal, ethnic, religious, racial, and national affairs, and even on an interplanetary level in the future. The resulting disinformation and bias may aim simply at distraction of the targeted entity or at gaining a partial, even absolute, control over the entities informed.

With regard to alignment of interests,

- The very first question to be asked is what kind of alignment of interest exists between the source and the entity informed-whether there is any open (declared), implied, or only a potentially adversary conflict of interest, even only an association of the source with entities that may have conflicting interests with the entity informed.

- A similar question must be asked about whether there is any divergence or disparity of interests. The purpose of such a question is to asses the likelihood of disinformation or intentional bias in the information value provided.

- A milder version of the same types of questions is whether there is any history of outright disinformation of a general nature, such as fabrication of new or intentional bias in their presentation but not necessarily targeting a specific entity informed. It may come from greed, longing for vain glory, etc., as it can be easily observed in all mass media.

In court proceedings, there are many legally prescribed precautions. Certainly, all commercials, particularly from companies without established brands and tradition, must be subject to a special scrutiny with respect to the level of bias.

Next, one must test the more intrinsic factors of the source's reputation, such as its reliability in yielding the value of interest with a source-specific credibility that depends on the offered verifiability, replicability, or warranty that increases the source's reputation, and any imperfections in definition, variability, objectivity, accuracy, precision, and currency that decreases it (Gackowski, 2006). The latter six imperfections affect presentation credibility in indirect informing the same way; however, only definitions and objectivity are subject to bias and are less likely to be outright disinformation.

Verifiability takes various forms. One of them is accreditation of the source by a reputable professional body, which periodically verifies the source's eligibility for its accreditation status. Another form is whether the source is subject to a legally mandated periodical audit as it applies to public corporations. Similarly, a source is verifiable when it is bonded or legally responsible for the information service it provides. For instance, all commercial offers on Web sites and by email could be voluntarily registered with a commercial unit (never a government agency) that, in case of a dispute, guarantees to a certain level that the claims are legitimate. Entities informed should know to what extend their risk is limited when dealing with each partner and that commercial deals with non-registered partners are completely at their own risk.

Replicability may be another form of assurance of quality in a credible manner when the source enables replication of some tests. For instance, a specimen might be preserved for additional testing later when doubts may arise or claims are challenged.

Warranty is another form of quality assurance. It is particularly convincing when combined with bonding. Usually it assures that proper seriously observed procedures are in place. The amount of warranty offered indicates by how much the entity's informed risk is diminished in case of quality defects.

Uncertainties associated with the definition of what specific data represent in the real world automatically decrease by this much the final credibility of the concerned value. 
Loss of objectivity, meant as free of bias, may happen in the process of data/information acquisition due to the approaches and methods used in selecting the primary sources, measuring and observation points, measuring instruments, and, finally, when collecting, processing, and presenting data. The resulting bias may be either unintended due to ignorance or introduced intentionally. The results of distortions may be significant, hence deceptive, and damaging to the source's reputation. To rectify the bias and compensate for it may require engagement of substantial additional resources. Whether it is economically justified can be assessed only when its impact on operations is known. As in other cases, this will affect the direct secondary operations quality requirement of economically actionable credibility (Gackowski, 2005b).

Mapping quality is a function of the design and operations of any data/information delivery system. As long as it is fully automated with a minimum of human intervention, it is an unlikely source of intentional bias and disinformation as long it is securely kept, run, and protected against intrusion from outside and inside of the organization. In today's networked environments with access to the Internet, it becomes more and more doubtful. Error self-detection and error selfcorrection codes, firewalls around networked computers, and detection of and protection from software viruses and worms are some of the possible counter measures.

Each of the discussed factors directly and independently impairs the final level of credibility of the affected value, and none of them compensates for the losses of credibility caused by other factors

\section{Conclusions}

In everyday life, commerce, and politics, bias and disinformation is not an exception or aberration. It is inherent to all communications among living entities and systems controlled by them. Any society capable of preventing or at least satisfactorily limiting abuses in public communications by either side of the communication channels, informing entities, and entities informed will reap the benefits from sharing the achievements of human creativity and avoid the waste from abuse of the free exchange of information. All informing systems should be designed with appropriate counter measures that protect both sides from bias, disinformation, and piracy to an economically acceptable degree.

It seems that there is also a need to extend the current Informing Science Framework introduced by Eli Cohen (1999) to the following: "Informing science is a field of inquiry that attempts to provide entities informed with quality information with regard to content, form, format, and schedule that maximize the effectiveness of operations of informing entities and entities informed" (added words in bold). The term "client" should be broadened to "entities informed." The term "clients" in its meaning in commerce, client/server computing, and program objects relationships do not cover all situations of interest.

These conclusions, certainly incomplete, are presented for critique, challenge, and discussion and for sharing of better ideas that may limit bias and outright disinformation in the free exchange of information.

\section{References}

Cohen, E. (1999). Reconceptualizing information systems as a field of the transdiscipline informing science: From ugly duckling to swan. Journal of Computing and Information Technology, 7(3), 213-219. Retrieved from http://inform.nu/WhatsIS.htm

Electronic Standard Book Number (ESBN). (2006). Retrieved from http://numly.com/esbn/default.asp

Encyclopedia Britannica. (2005). Information system. Retrieved April 22, 2005, from Encyclopedia Britannica Online. http://search.eb.com/eb/article?tocId=218074 
Encyclopedia Britannica. (2006). Political philosophy. Retrieved January 6, 2006, from encyclopedia Britannica Online http://search.eb.com/eb/article-10229

Financial Accounting Standard Board (FASB). (1983). Accounting standard: Statement of financial accounting concepts. New York, NY: McGraw-Hill.

Gackowski, Z. J. (1982). An approach to categorization of information systems. Proceedings of the ASIS (American Society for Information Science) Annual Meeting, Volume 19, Columbus, OH.

Gackowski, Z. J. (2004). Logical interdependence of data/information quality dimensions-A purposefocused view on IQ. Proceedings of the Ninth International Conference on Information Quality (ICIQ04), Cambridge, Massachusetts. Retrieved from http://www.iqconference.org/Documents/IQ Conference 2004/Papers/LogicalInterdependence.pdf

Gackowski, Z. J. (2005a). Informing systems in business environment: A purpose-focused view. Informing Science Journal, 8, 101-122. Retrieved June 27, 2005, from http://inform.nu/Articles/Vol8/v8p101122Gack.pdf

Gackowski, Z. J. (2005b). Operations quality of data and information: Teleological operations researchbased approach, call for discussion. Proceedings of the 10th Anniversary International Conference on Information Quality_ICIQ-05 at Massachusetts Institute of Technology (MIT), Cambridge, MA.

Gelman, I. A. (2005). A theory of complementarity of extracting accurate data from inaccurate sources through integration. Proceedings of the $10^{\text {th }}$ International Conference on Information Quality (ICIQ05), Cambridge, Massachusetts.

Hamlyn, D. W. (1980). Schopenhauer: The arguments of philosophers. London, UK: Routeledge \& Kegan Paul.

Mosca, G. (2006). Encyclopedia Britannica. Retrieved March, 8, 2006, from Encyclopedia Britannica Online http://search.eb.com/eb/article-9053877

Nadler, G. (1970). Work systems design: The IDEAL concept. Homewood, IL: Richard D. Irwin.

Schopenhouer, A. (1974). The fourfold root of the principle of sufficient reason (E. G. Payne, Trans.). La Salle, IL: Open Court.

Wand, Y., \& Wang R. Y. (1996). Anchoring data quality dimensions in ontological foundations. Communications of the ACM, 39(11), 86-95. Retrieved from https://www.crg2.com/iqconference/documents/publications/TDQMpub/WandWangCACMNov96.pdf

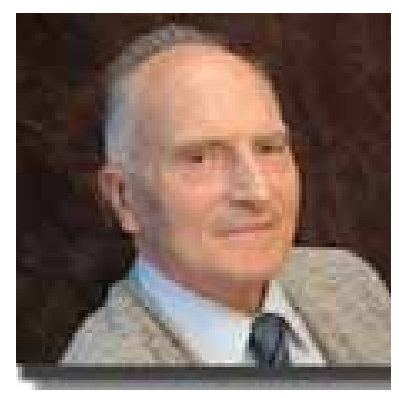

\section{Biography}

Zbigniew J. Gackowski has extensive experience in industry, public administration, and universities. His teaching and research bridge the gap between Central European and US experience in Computer Information Systems (Warsaw Polytechnic, the University of Michigan [Fulbright Research Scholarship], Purdue University [Visiting Associate Professor], Baruch College [Visiting Professor], California State University, Stanislaus [Professor], and the University of Melbourne [Visiting Professor]). His research has received much recognition. While in Poland, he published more than 120 items, among them, 4 books, and 6 papers in refereed journals, 12 papers presented across Europe, the United States, the Middle East, and South America. While in the USA, he taught at three universities and presented 15 research papers published in the proceedings of ASIS, ACM, DSI, Information Systems Educators Conference, The Informing Science Institute, and the International Conference on Information Quality at MIT. He is a member of ACM and DSI and is a charter member of the Association for Information Systems and the Institute of Informing Science. His resent research focuses on quality of data and information values in informing. 